ARTIGO

Recebido em: 01/06/2017

Aceito em: $12 / 07 / 2018$

\title{
Produção científica brasileira em Química entre 2004 e 2013: análise dos artigos indexados na Web of Science
}

\author{
Brazilian scientific production in Chemistry between 2004 and \\ 2013: analysis of articles indexed in the Web of Science
}

\author{
Sabrina Diehl MENEZES (sabrina.menezes@ufrgs.br)* \\ Sonia Elisa CAREGNATO (sonia.caregnato@ufrgs.br)** \\ * Mestre em Comunicação e Informação pela Universidade Federal do Rio Grande do Sul (UFRGS) e \\ Bibliotecária da Universidade Federal do Rio Grande do Sul (UFRGS). \\ ** Professora da Universidade Federal do Rio Grande do Sul (UFRGS), Faculdade de Biblioteconomia e \\ Comunicação; Programa de Pós-graduação em Comunicação e Informação - PPGCOM.
}

\begin{abstract}
Resumo
Analisa a produção científica brasileira em Química publicada entre 2004 e 2013 na forma de artigos científicos. O corpus da pesquisa é composto por 42.954 artigos científicos coletados na base de dados da Web of Science. Os resultados mostram que a produção científica em Química cresceu linearmente durante os dez anos estudados. A taxa de crescimento é de $6,29 \%$ ao ano e de $73,19 \%$ no período completo, e sua contribuição para o total da produção nacional é de 15,5\% e para a mundial da área de 1,95\%. 0 Índice de atividade é de 0,79 e aponta para um desenvolvimento abaixo da média mundial para a área. A distribuição geográfica da produção científica em Química apresenta grande desigualdade entre as regiões brasileiras; as regiões Sudeste e Sul se destacam pelo número de artigos publicados, respectivamente $57 \%$ e $17,97 \%$ do total. Constata-se que um pequeno núcleo de instituições brasileiras foi responsável pela publicação de 52,41\% do total de artigos. As instituições com maior produtividade na área são USP (13,93\%) e Unicamp (7,83\%). A internacionalização da pesquisa em Química é observada pelo percentual de artigos publicados em inglês $(92,08 \%)$ e em periódicos estrangeiros (83,65\%). A maior parte dos artigos da área tem colaboração nacional, porém um percentual de $24 \%$ tem coautoria com pesquisadores estrangeiros. A coautoria bilateral é predominante entre artigos publicados em colaboração internacional. Os resultados apontam para o crescimento constante da área e para a internacionalização da pesquisa Química brasileira.
\end{abstract}

Palavras-chave: Produção Científica. Indicadores Bibliométricos. Química.

\begin{abstract}
The paper analyzes the Brazilian scientific production in Chemistry published between 2004 and 2013 as scientific articles. The corpus of the study is composed of 42,954 scientific articles selected in the Web of Science database. The results show that Brazilian scientific production in chemistry increased linearly during the ten years studied, with a growth rate of $6.29 \%$ per year and $73.19 \%$ in the whole period. Its contribution to total domestic production is $15.5 \%$ and to world production in Chemistry is $1.95 \%$. There is great inequality among Brazilian regions in relation to their productivity. The Southeast and South regions stand out for the number of published articles. Most of the articles have national co-authors, but a percentage of $24 \%$ was co-authored with foreign researchers. Bilateral coauthorship is prevalent among articles published in international collaboration. The results point to the steady growth of the area and for to the internationalization of Brazilian chemical research.

Keywords: Scientific Production. Bibliometric Indicators. Chemistry.
\end{abstract}

v. 23, n. 53,2018 p. $25-38$

ISSN 1518-2924

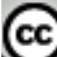




\section{INTRODUÇÃO}

O progresso científico e tecnológico é fator determinante no desenvolvimento socioeconômico de um país. Tanto a ciência quanto a tecnologia são atividades que necessitam de um investimento forte e contínuo de recursos humanos, materiais e financeiros. Países desenvolvidos e os que aspiram ao desenvolvimento investem constantemente nestas áreas. Os dados da National Science Foundation (2018) apontam que, em 2015, os países que mais investiram em Pesquisa e Desenvolvimento (P\&D) no mundo foram os Estados Unidos (497 bilhões de dólares), China (409 bilhões) e Japão (170 bilhões). Juntas, essas nações somam mais de 50\% do total de investimentos feitos em P\&D no mundo inteiro (1.91 trilhões de dólares). 0 Brasil, em 2015, despendeu 98 bilhões de reais em C\&T (1,64\% do PIB nacional), destes, 50,2\% provenientes do setor público e $49,8 \%$ do setor empresarial (BRASIL, 2017).

É notório que países em desenvolvimento financiam suas pesquisas com recursos oriundos principalmente do setor público, enquanto que países desenvolvidos têm o setor privado como forte aliado para o seu progresso científico (CONTINI; SÉCHET, 2005). Diante disso, tanto as instituições privadas quanto os órgãos ou agências de fomento públicos necessitam eleger áreas e instituições que receberão os insumos destinados ao desenvolvimento de pesquisas. Mueller (2008) esclarece que as agências de fomento precisam de sistemas de avaliação para verificar e conhecer o que é produzido no país e identificar e instigar o desenvolvimento de projetos de pesquisa qualificados, com base nas metas e objetivos propostos pelo governo para a Ciência.

A produção científica é o conjunto de documentos publicados nos canais de comunicação reconhecidos pela comunidade científica e, por isso, constitui-se no corpo de conhecimentos científicos produzidos ao longo dos anos pelos pesquisadores de cada especialidade. Devido a sua própria natureza, ela é um dos elementos chave na avaliação da ciência, uma vez que, a publicação dos resultados de pesquisa é parte concreta e visível de todos os procedimentos e investimentos feitos. Com a publicação dos resultados tem-se o retorno para a sociedade - na forma de novos conhecimentos - das atividades desenvolvidas pelos pesquisadores em seu ambiente de trabalho.

Os indicadores de output, que mensuram os resultados desses investimentos por meio da análise da produção científica (MUELLER, 2008; NORONHA; MARICATO, 2008), têm sido os principais métodos de avaliação da ciência. Por meio destes indicadores é possível realizar estudos bibliométricos que mapeiam e identificam as principais características de uma determinada ciência em seu contexto nacional e internacional.

Além disso, a análise da produção científica contribui significativamente para a compreensão do desenvolvimento das áreas do conhecimento. Em âmbito nacional, este tipo de estudo permite, entre outros aspectos, verificar o status de desenvolvimento da ciência nacional e compará-la com o que se tem produzido em nível internacional, podendo auxiliar na tomada de decisão e na elaboração de políticas científicas para o país. Essas políticas norteiam o desenvolvimento de novas frentes de pesquisas, bem como, possibilitam uma distribuição equitativa de recursos financeiros para as diferentes instituições de pesquisa.

A Química tem sido uma das principais ciências responsáveis pelo desenvolvimento nacional. É considerada uma ciência central, pois suas descobertas, conceitos e aplicações permutam entre diversas áreas do conhecimento, auxiliando o desenvolvimento de novas pesquisas. Pertencente às Ciências Exatas, este campo científico é um dos principais fatores no desenvolvimento de novos produtos e tecnologias que impulsionam o avanço científico e tecnológico da sociedade. Além disso, é uma área que tem aplicabilidade em diversos setores da indústria nacional. Em 2013, o Brasil situou-se na sexta posição no ranking mundial de faturamento das indústrias químicas (ASSOCIAÇÃO BRASILEIRA DE INDÚSTRIA QUÍMICA, 2015)

Neste contexto, esta pesquisa tem por objetivo geral analisar as características apresentadas pela Química brasileira com base na sua produção científica publicada no período entre 2004 e 2013 e indexada na base de dados Web of Science. São três os objetivos específicos: examinar o desenvolvimento da Química brasileira por meio de sua produção científica; verificar a distribuição geográfica e institucional da produção científica brasileira em Química; analisar a internacionalização da produção científica em Química por meio dos indicadores de idioma, periódicos e colaboração internacional. 


\section{MATERIAL E MÉTODOS}

Esta pesquisa é do tipo bibliométrica e caracteriza-se por ser descritiva e de nível macro, pois analisa a produção científica de um país, embora com foco em uma área específica do conhecimento, neste caso a Química. Tem cunho quantitativo, considerando-se o uso de medidas da estatística básica para identificar padrões e comportamentos da área ao longo do período estudado (2004-2013).

Os dados de produção científica foram coletados na base de dados Web of Science (WoS). A escolha por esta base de dados em detrimento de outras mais especializadas na área Química se deve ao fato da possibilidade de se coletar dados completos (filiação de todos os autores, palavras-chave, título, resumo, referências, citações recebidas, etc.), de cada artigo brasileiro publicado na área. A WoS tem uma cobertura considerada excelente em áreas que compõem as ciências duras. Moed (2005) apontava que a WoS cobria $90 \%$ das principais publicações na área Química já em 2005.

A estratégia de busca adotada foi elaborada principalmente com base nas categorias de periódicos (WC) da WoS que se relacionam com a área em questão. A opção pela busca por meio das categorias WC e não por palavras-chave deve-se ao fato de a Química ser uma área ampla e complexa, o que tornaria a busca por palavras-chaves extremamente extensa e possivelmente incompleta. Diante disso, optou-se pelo uso das categorias de assunto/ periódicos (WC) definidas no estudo de Glanzel e Schubert (2003) como pertencentes à Química. A utilização dessas categorias possibilita comparações deste estudo com outros estudos já publicados e que se utilizaram da mesma metodologia. Glanzel e Schubert (2003) ao analisarem artigos, categorias de periódicos e classificações de pesquisadores da cientometria, concomitante à avaliação de especialistas das áreas, classificaram as temáticas em áreas do conhecimento com o objetivo de padronizar e facilitar a análise nos estudos bibliométricos. Na área específica de Química, os autores encontraram 20 categorias que englobam o maior número de temáticas pesquisadas por esta ciência. Nesse sentido, as 20 categorias WC utilizadas como expressão de busca na WoS foram: Química Multidisciplinar, Química Analítica, Química Inorgânica e Nuclear, Espectroscopia, Química Aplicada, Engenharia Química, Química Medicinal, Química Orgânica, Termodinâmica, Físico-Química, Eletroquímica, Ciência dos Polímeros, Ciência dos Materiais Papel e Madeira, Ciência dos Materiais Cerâmicos, Ciência dos Materiais Multidisciplinar, Engenharia Metalúrgica e Metalurgia, Ciência dos Materiais Caracterização e Teste, Ciência dos Materiais Revestimentos e Películas, Ciência dos Materiais Compostos, Ciência dos Materiais Têxteis.

Sabendo-se que o artigo científico é considerado o principal meio de comunicação das ciências duras, optou-se por limitar este estudo a esta tipologia documental, que tem por característica publicar resultados originais e completos de pesquisa. Diante disso, o corpus final da pesquisa foi composto por 42.954 artigos publicados de 2004 a 2013, indexados na Web of Science e com ao menos um autor brasileiro que publicou artigos pertencentes a alguma das categorias de assunto/periódicos definidas acima. A análise específica por nome de autor e sua respectiva titulação/profissão não é objetivo desta pesquisa, portanto, consideram-se como autores brasileiros da área Química todos aqueles que publicaram artigos nessa temática e que tenham especificado o nome Brasil no campo de endereço institucional.

No que se refere ao tratamento e à análise de dados, utilizou-se principalmente o software Bibexcel, que permite a remoção de registros duplicados e a realização de variadas análises estatísticas básicas. Para manter uma consistência maior, padronizar as informações coletadas e corrigir eventuais inconsistências da base de dados, fez-se uma limpeza profunda nas informações relativas às instituições. Havia, inicialmente, 9.897 instituições, recuperadas com base nos dados de filiação dos autores. Após a limpeza e remoção das diversas variações dos nomes, o número total de instituições passou para 3.466. A limpeza referente aos periódicos científicos também se tornou necessária, uma vez que foram detectadas inconsistências nos nomes, resultando em duplicidade de títulos. 


\section{RESULTADOS E DISCUSSÃo}

\subsection{Crescimento da produção científica brasileira em Química}

A Química brasileira obteve um crescimento médio geométrico anual de 6,29\% no número de artigos publicados e um aumento total de 73,19\% no período entre 2004 e 2013. Em contrapartida, no mesmo período, seu crescimento foi inferior tanto à média geométrica nacional $(10,25 \%)$ quanto ao crescimento total da produção científica nacional $(140,58 \%)$. A Química nacional superou a média geométrica de crescimento anual da produção científica mundial $(5,15 \%)$ e, também, o crescimento total $(57,12 \%)$. O mesmo ocorreu com a produção mundial em Química, que teve crescimento anual de 5,00\% e total de 55,12\%. Além disso, entre 2004 e 2013 observa-se um crescimento linear da produção científica em Química, demonstrado pelo coeficiente de correlação linear $\mathrm{R}^{2}$ igual a 0,964.

Entre uma gama de possíveis fatores que podem ter auxiliado no incremento da produção científica em Química, dois se destacam. 0 primeiro fator foi o aumento no número de periódicos brasileiros indexados na WoS. Estudos como os de Leta et al. (2013) e de Vargas et al. (2014) mencionam que o crescimento no número de periódicos brasileiros na WoS tem sido uma das causas que proporcionaram o aumento da produção científica nacional nos últimos anos. Adicionalmente, Testa (2011) aponta que o Brasil está entre os três países (Espanha, Brasil e Austrália) que obtiveram o maior número de periódicos indexados (105 títulos) na WoS entre 2005 e 2010. Diante disso, os dados de crescimento encontrados sobre a produção científica brasileira em Química podem estar relacionados à mudança ocorrida na cobertura de periódicos da WoS, considerando-se que dos nove periódicos nacionais utilizados pelos pesquisadores brasileiros da área para publicar os artigos analisados nesta pesquisa, somente três estavam indexados na WoS em 2007, e a maioria passou a ser indexada entre 2008 e 2010.

O segundo fator relevante é o crescimento da pós-graduação brasileira em Química no período de tempo estudado. Quando os dados da pós-graduação são comparados com a produtividade da área, no período entre 2004 e 2013, verifica-se que a produção científica brasileira em Química apresenta uma taxa de crescimento médio geométrico anual muito próxima da taxa referente ao número de docentes e ao de discentes matriculados e titulados. À medida que o número de docentes cresceu em média geométrica de $6,28 \%$ ao ano e o número de discentes matriculados e titulados também cresceu, respectivamente 6,93\% e $7,46 \%$ ao ano, a produção científica nacional da área progrediu com média geométrica de 6,29\% no período estudado. 0 crescimento total da pós-graduação em Química também é similar ao crescimento total da produção científica da área. Enquanto o número de docentes aumentou em 73,01\%, o número de discentes matriculados em $82,80 \%$ e de discentes titulados em 91,03\%, a produção científica nacional em Química obteve um crescimento de $73,19 \%$ no período entre 2004 e 2013. Esse fato demonstra que, aparentemente, o crescimento no número de docentes de pós-graduação ocasionou um aumento na produtividade da área.

No que se refere ao percentual de contribuição da Química brasileira para a produção científica mundial da área, constata-se que, entre 2004 e 2013, ela colaborou com $1,95 \%$ do total produzido no mundo na sua especialidade. No contexto nacional, a Química aumentou sua contribuição quando comparada com períodos anteriores a 2004. De acordo com Leta e De Meis (1996), no período entre 1981 e 1993, a Química representava 8,4\% da produção nacional. No estudo de Vanz (2009) foi constatado que a Química era a área mais produtiva da Ciência brasileira entre 2004 e 2006, representando 15,2\% da produção científica nacional. Com resultado similar ao de Vanz (2009), esta pesquisa observou que a Química foi responsável pela publicação de 15,5\% da produção científica brasileira no período entre 2004 e 2013, demonstrando a boa produtividade da área no país.

0 Índice de Atividade empregado nesta pesquisa é um indicador relativo que averigua o esforço empreendido por um país no desenvolvimento das áreas do conhecimento. Algumas áreas apresentam um índice maior que outras quando a disciplina é bem desenvolvida e, do lado oposto, um baixo índice reflete áreas com pouca atividade científica no país. Diante disso, observou-se que, no período de análise completo (20042013), o Índice de Atividade para a Química brasileira foi de 0,79, isto é, 31\% abaixo da média mundial, que tem valor 1 . Esse resultado é compreensível, considerando-se que o 
Brasil pertence ao grupo de países que se enquadram no modelo denominado "Bioenvironmental model", cujas áreas de pesquisa são principalmente: Agricultura e Ciências da Terra, Biologia e Ciências Espaciais. Este modelo não engloba a Química, que é privilegiada no "japanese model". Diante disso, pode-se compreender que a produtividade científica brasileira seja maior na Agricultura e Biologia, e, por isso, o Índice de Atividade é maior nestas áreas, entre 1,5 e 2,0, isto é, acima da média mundial e superior à média da Química (LETA et al., 2013).

\subsection{Distribuição geográfica e institucional da pesquisa em Química no Brasil}

A pesquisa Química brasileira foi desenvolvida e publicada por pesquisadores filiados a instituições brasileiras oriundas de todas as cinco regiões do país e de todos os 27 Estados, embora com acentuadas diferenças em relação à contribuição de cada um para a produção científica brasileira em Química no período entre 2004 e 2013. Assim como ocorre com a produção científica nacional, a Região Sudeste é aquela que concentra a maior parte $(57,00 \%)$ dos artigos brasileiros em Química, com o triplo do número de artigos da Região Sul $(17,97 \%)$ e o quádruplo da Região Nordeste $(13,13 \%)$. A predominância das publicações da Região Sudeste pode ser explicada por alguns dos fatores apontados pela Fundação de Amparo à Pesquisa do Estado de São Paulo (FAPESP) (2011), tais como: infraestrutura de P\&D, quantidade de pesquisadores e recursos humanos especializados disponíveis e maior volume de investimentos nesta região. Provenientes destes fatores, dois aspectos também podem ser elencados como propulsores do desenvolvimento da pesquisa em Química nestas regiões: os grupos de pesquisa e os cursos de pós-graduação da área.

Dos 927 grupos de pesquisa cadastrados no Conselho Nacional de Desenvolvimento Científico e Tecnológico (CNPq) como pertencentes à área Química, 44,88\% estão localizados na Região Sudeste enquanto somente 6,15\% dos grupos atuam na Região Norte do país. Ou seja, a Região Sudeste, que é a mais produtiva, apresenta o maior número de grupos de pesquisa e a Região Norte, que é a menos produtiva, tem poucos grupos de pesquisa localizados em seus Estados. Por outro lado, observa-se uma inversão de posição quando se analisa a Região Nordeste e a Sul, pois, enquanto a Região Sul é mais produtiva do que a Nordeste, esta última tem um número maior de grupos de pesquisa do que a Região Sul (Tabela 1). Esse resultado pode se relacionar com a crescente expansão das pesquisas realizadas na Região Nordeste que, segundo Sidone et al. (2016), aumentou em 6\% a sua produção científica.

A distribuição dos cursos de mestrado e doutorado parece ter relação direta com a produção científica, pois a quantidade de artigos publicados é maior nas regiões em que há um número maior de programas de pós-graduação em Química. O Sudeste apresenta o dobro do número de programas da Região Sul e Nordeste, assim como apresenta o triplo da produtividade da Região Sul e o quádruplo da Região Nordeste. A Região Norte é a que concentra o menor número de programas de pós-graduação e a menor quantidade de grupos de pesquisa e, possivelmente, este fato influencia no desenvolvimento das pesquisas Químicas nesta região, considerando-se que a produção científica da área representa somente $1,48 \%$ do total (Tabela 1). Além disso, as regiões Sudeste e Sul são aquelas onde se localizam os nove programas de pós-graduação que receberam nota 7 na avaliação trienal da Coordenação de Aperfeiçoamento de Pessoal de Nível Superior (CAPES) de 2013, ou seja, nota máxima. Na Região Nordeste, por outro lado, a melhor nota chegou ao valor seis e as regiões Norte e Centro-Oeste não obtiveram notas superiores a cinco. 
Tabela 1: Distribuição dos programas de pós-graduação em Química, dos grupos de pesquisa em Química e da quantidade de artigos publicados.

\begin{tabular}{|c|c|c|c|c|c|c|c|c|c|}
\hline 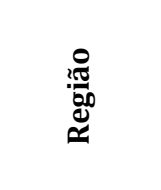 & 高 & $0^{\circ}$ & 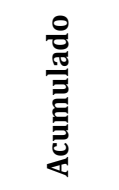 & 온 & $0^{0}$ & 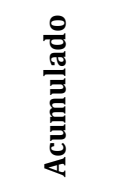 & 总 & $\partial^{e}$ & 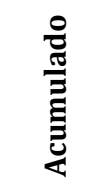 \\
\hline Sudeste & 27 & 42,19 & 42,19 & 416 & 44,88 & 44,88 & 47.097 & 57,00 & 57,00 \\
\hline Sul & 13 & 20,31 & 62,50 & 171 & 18,45 & 63,32 & 14.851 & 17,97 & 74,98 \\
\hline Nordeste & 13 & 20,31 & 82,81 & 211 & 22,76 & 86,08 & 10.849 & 13,13 & 88,11 \\
\hline $\begin{array}{c}\text { Centro- } \\
\text { oeste }\end{array}$ & 8 & 12,50 & 95,31 & 72 & 7,77 & 93,85 & 2.791 & 3,38 & 91,48 \\
\hline Norte & 3 & 4,69 & 100,00 & 57 & 6,15 & 100,00 & 1.219 & 1,48 & 92,96 \\
\hline $\begin{array}{c}\text { Brasil em } \\
\text { Geral* }\end{array}$ & - & - & - & - & - & - & 5.817 & 7,04 & 100,00 \\
\hline Total & 64 & 100,00 & - & 927 & 100,00 & - & 82.624 & 100,00 & - \\
\hline
\end{tabular}

*Brasil em Geral= refere-se aos artigos publicados por instituições brasileiras cujas atividades estão distribuídas por diversas regiões e estados do país, tais como a EMBRAPA.

Legenda: PPG - Programa de Pós-Graduação. GP - Grupos de Pesquisa

Fonte: dados da pesquisa, 2016.

Em relação à produtividade dos Estados brasileiros, observa-se que somente São Paulo acumula 35,98\% de toda a produção científica brasileira em Química, seguido pelo Rio de Janeiro (11,23\%), Minas Gerais (9,30\%) e Rio Grande do Sul (8,14\%). Os sete estados brasileiros mais produtivos representam juntos 81,52\% dos artigos da área e demonstram a predominância das regiões Sudeste e Sul como as principais produtoras de conhecimento científico nesta área. Por outro lado, seis estados da Região Norte do Brasil (Acre, Amapá, Tocantins, Roraima, Rondônia e Amazonas), somam somente $0,60 \%$ da produção científica brasileira em Química. O Pará é o estado da Região Norte com melhor produtividade e representa 0,88\% dos artigos brasileiros da área. A baixa produtividade científica desta região pode se justificar pelo escasso número de cursos de pós-graduação, considerando-se que, atualmente, somente quatro deles são oferecidos: dois com modalidade de mestrado e doutorado (Amazonas/UFAM e Pará/UFPA), e dois cursos com exclusivamente a modalidade mestrado (Roraima/UFT e Pará/UNIFESSPA), sendo que a melhor nota obtida por dois destes cursos na avaliação da CAPES foi quatro, enquanto os outros tiveram nota três.

A produção científica brasileira em Química foi publicada com autoria de 3.466 diferentes instituições, sendo 1.058 nacionais (30,52\% do total) e 2.408 estrangeiras $(69,47 \%)$. As instituições mais produtivas são todas brasileiras, considerando-se que a análise é de artigos brasileiros em Química e que 75,73\% deles foram publicados em coautoria com instituições nacionais. As 18 instituições que publicaram mais de 1.000 artigos foram responsáveis por $52,41 \%$ do total da produção científica em Química, enquanto as demais instituições (3.457) publicaram 42,59\% dos artigos. Constata-se, portanto, a existência de um pequeno núcleo de instituições que publicam mais acentuadamente e uma grande dispersão de entidades que publicam poucos artigos da área. As instituições brasileiras mais produtivas na área Química pertencem principalmente aos estados das regiões Sudeste e Sul, especialmente São Paulo, Rio de Janeiro, Minas Gerais e Rio Grande do Sul.

A instituição com maior produtividade em Química é a Universidade de São Paulo (USP), com 13,93\% do total de artigos publicados. A produtividade desta universidade é destacada das demais, inclusive da segunda colocada a Universidade Estadual de Campinas (UNICAMP), tendo em vista que ela publicou quase o dobro do total de artigos desta última. A Tabela 2 apresenta as principais instituições responsáveis pela produção científica brasileira em Química, com ponto de corte em 0,5\% de contribuição. De acordo com Leta (2011), a USP 
é a principal universidade brasileira em pesquisa, resultado originado por dois fatores: o primeiro relaciona-se com a concepção de criação desta universidade, que visava ser a primeira instituição de ensino superior com pesquisa no Brasil; o segundo está concatenado ao maciço e contínuo investimento da FAPESP na USP, que possibilita que haja recursos humanos qualificados e infraestrutura adequada à pesquisa e ao ensino.

Tabela 2: Principais instituições nacionais autoras dos artigos brasileiros em Química (2004-2013).

\begin{tabular}{|c|c|c|c|}
\hline Posição & Instituição & Total de Artigos & $\%$ \\
\hline 1 & USP & 11.511 & 13,93 \\
\hline 2 & UNICAMP & 6.471 & 7,83 \\
\hline 3 & UFRJ & 5.026 & 6,08 \\
\hline 4 & UNESP & 4.129 & 5,00 \\
\hline 5 & UFRGS & 3.284 & 3,97 \\
\hline 6 & UFSCAR & 3.222 & 3,90 \\
\hline 7 & UFMG & 3.029 & 3,67 \\
\hline 8 & UFSC & 2.706 & 3,28 \\
\hline 9 & $\begin{array}{l}\text { UFCE } \\
\end{array}$ & 1.982 & 2,40 \\
\hline 10 & UFPR & 1.905 & 2,31 \\
\hline 11 & $\overline{\text { UFPE }}$ & 1.662 & 2,01 \\
\hline 12 & CNEN & 1.405 & 1,70 \\
\hline 13 & $\overline{\text { UFSM }}$ & 1.372 & 1,66 \\
\hline 14 & UFF & 1.345 & 1,63 \\
\hline 15 & UEM & 1.135 & 1,37 \\
\hline 16 & UNB & 1.079 & 1,31 \\
\hline 17 & UFBA & 1.066 & 1,29 \\
\hline 18 & UFPB & 1.047 & 1,27 \\
\hline 19 & UFRN & 999 & 1,21 \\
\hline 20 & EMBRAPA & 854 & 1,03 \\
\hline 21 & UFU & 792 & 0,96 \\
\hline 22 & UFV & 768 & 0,93 \\
\hline 23 & PUC-Rio & 759 & 0,92 \\
\hline 24 & UFG & 698 & 0,84 \\
\hline 25 & CTA & 674 & 0,82 \\
\hline 26 & FIOCRUZ & 669 & 0,81 \\
\hline 27 & UERJ & 656 & 0,79 \\
\hline 28 & UFSE & 635 & 0,77 \\
\hline 29 & UFPA & 622 & 0,75 \\
\hline 30 & UFOP & 609 & 0,74 \\
\hline 31 & UNIFESP & 589 & 0,71 \\
\hline 32 & UFJF & 557 & 0,67 \\
\hline 33 & Petrobras & 545 & 0,66 \\
\hline 34 & UENF & 518 & 0,63 \\
\hline 35 & UFABC & 507 & 0,61 \\
\hline \multirow[t]{4}{*}{36} & UEL & 484 & 0,59 \\
\hline & Total parcial & 65.311 & $79,05 \%$ \\
\hline & Demais Instituições & 17.313 & $20,95 \%$ \\
\hline & Total & 82.624 & 100,00 \\
\hline
\end{tabular}

Fonte: dados da pesquisa, 2016.

Quando somados os três tipos de universidades públicas (municipais, estaduais e federais), verifica-se que esta tipologia constitui a maioria das instituições brasileiras. Consequentemente, grande parte dos artigos foi publicada por pesquisadores vinculados a universidades públicas federais $(49,86 \%)$ e universidades públicas estaduais $(32,37 \%)$. Este resultado reflete o já exposto em diversos estudos sobre a ciência brasileira (LETA et al. 2006; LETA, 2012), que indicam que a pesquisa nacional é majoritariamente realizada em universidades públicas. 
No que se refere à colaboração existente entre universidades e outros tipos de instituições na realização de pesquisas científicas, constata-se que isso ocorre nos grandes centros e capitais das Regiões Sudeste e Sul, onde há o predomínio de universidades públicas. Ao se analisar a tipologia institucional (Tabela 3), observa-se que, em dados absolutos, as empresas constituem o maior número $(36,11 \%$ do total) de instituições brasileiras coautoras dos artigos em Química, embora elas representem somente 1,27\% do total de artigos publicados porque a maioria é responsável por um único artigo. As instituições privadas correspondem a $8,41 \%$ do total de instituições e publicaram menos de $0,40 \%$ dos artigos químicos brasileiros. As empresas brasileiras que se destacam pela produtividade são: Braskem (95 artigos), Companhia Vale Rio Doce (32 artigos) e Usiminas (29 artigos). Entre as instituições privadas destacam-se o SENAI (54 artigos), o LACTEC (48 artigos) e a Sociedade Educacional de Santa Catarina (20 artigos).

Tabela 3: Distribuição dos artigos brasileiros em Química por tipo de instituições brasileiras autoras dos artigos em Química (2004-2013).

\begin{tabular}{c|c|c|c|c}
\hline Tipo & Artigos & $\mathbf{\%}$ & $\begin{array}{c}\text { Quantidade de } \\
\text { Instituições }\end{array}$ & $\mathbf{\%}$ \\
\hline Universidade Pública Federal & 41.199 & 49,86 & 61 & 5,77 \\
\hline Universidade Pública Estadual & 26.750 & 32,37 & 39 & 3,69 \\
\hline Instituição Pública Federal & 7.207 & 8,72 & 121 & 11,44 \\
\hline Universidade Privada & 4.452 & 5,39 & 210 & 19,85 \\
\hline Instituição Pública Estadual & 1.254 & 1,52 & 100 & 9,45 \\
\hline Empresa & 1.049 & 1,27 & 382 & 36,11 \\
\hline Instituição Privada & 292 & 0,35 & 89 & 8,41 \\
\hline Universidade Pública Municipal & 306 & 0,37 & 10 & 0,95 \\
\hline Hospital & 87 & 0,11 & 26 & 2,46 \\
\hline Instituição Pública Municipal & 22 & 0,03 & 15 & 1,42 \\
\hline Outras & 13 & 0,02 & 5 & 0,47 \\
\hline Total & 82631 & 100,00 & 1058 & 100,00 \\
\hline
\end{tabular}

Fonte: dados da pesquisa, 2016.

\subsection{Indicadores de internacionalização da pesquisa brasileira em Química}

Quando se analisa a produção científica de uma área, é possível identificar se sua pretensão é atingir uma audiência internacional ou se o seu foco é somente o público nacional. Entre os principais aspectos da produção científica que apontam para a busca pela internacionalização da pesquisa estão: idioma dos artigos publicados, periódicos utilizados para publicação e a colaboração internacional.

No que concerne ao idioma dos artigos publicados pela Química brasileira, nota-se que os pesquisadores preferem publicar artigos em inglês, pois 92,08\% deles foram escritos neste idioma e somente $7,77 \%$ foram redigidos na língua portuguesa no período entre 2004 e 2013. A predominância pelo idioma inglês pode relacionar-se com o pertencimento da Química às Ciências Exatas, às quais publicam pesquisas que contêm principalmente caráter experimental e foco internacional, como já esclarecido por Leta (2012), quando apontou que as Ciências Exatas e da Terra, Engenharias e Biologia tendem a realizar pesquisas internacionais, publicar em periódicos estrangeiros e, consequentemente, publicar no idioma inglês. Além disso, o alto percentual de artigos publicados em inglês permite inferir que os pesquisadores da área almejam alcançar uma audiência internacional para suas pesquisas. Por outro lado, constata-se que, no período de dez anos, houve um crescimento médio anual maior em artigos publicados em português $(10,68 \%)$ do que em inglês $(6,10 \%)$ e espanhol $(3,81 \%)$. 0 aumento no número de artigos em português ocorreu entre 2007 e 2008, época em que cresceu o número de periódicos nacionais indexados na WoS, inclusive alguns dos utilizados pelos pesquisadores brasileiros em Química.

Em relação aos periódicos científicos, verifica-se que dos 945 periódicos utilizados para publicar os artigos de química brasileiros, 11,52\% deles publicaram no mínimo 100 artigos cada e correspondem a $61,81 \%$ de toda a produção científica brasileira em Química entre 2004 e 2013. Há, portanto, um núcleo pequeno de periódicos que concentram a maior parte da produção científica brasileira em Química e uma grande dispersão de revistas científicas $(88,48 \%)$ que publicaram poucos artigos brasileiros da área. No que concerne ao idioma dos periódicos, apura-se um percentual expressivo de revistas que publicam somente 
em inglês $(85,82 \%)$ e um percentual menor de periódicos que publicam em mais de um idioma $(12,28 \%)$ e somente em português $(0,63 \%)^{1}$. O predomínio do inglês como idioma oficial dos periódicos justifica o alto percentual de artigos químicos brasileiros publicados nesta língua.

A maioria dos periódicos é de origem estrangeira e somente $0,95 \%$ são nacionais (nove títulos), consequentemente, 83,65\% dos artigos da Química brasileira foram publicados em periódicos estrangeiros enquanto $16,35 \%$ em periódicos brasileiros. Cabe destacar que os Estados Unidos e a Inglaterra concentraram mais da metade dos periódicos utilizados para publicação. Uma das possíveis causas para a priorização da publicação brasileira em periódicos estrangeiros pode se relacionar com as temáticas desenvolvidas pela Química, que são, muitas vezes, de interesse internacional. Outros fatores a serem considerados são a busca por uma maior visibilidade da pesquisa científica em âmbito mundial e a avaliação da pós-graduação nacional, que incentiva os pesquisadores a publicarem em periódicos estrangeiros indexados.

Embora haja preferência por periódicos estrangeiros, observa-se que todos os periódicos nacionais utilizados estão entre os $11,52 \%$ que compõem o pequeno núcleo com maior número de artigos da Química brasileira. Ademais, entre as dez revistas científicas que mais publicaram artigos brasileiros em Química, cinco são nacionais, fato que evidencia também o padrão internacional da maioria dos periódicos nacionais da área. Este resultado demonstra que os periódicos nacionais, embora sejam em pequeno número nesta pesquisa, são importantíssimos para o desenvolvimento da pesquisa científica brasileira na área e são os veículos de comunicação mais frequentemente utilizados pelos pesquisadores brasileiros (Tabela 4).

Tabela 4: Dez principais periódicos utilizados pelos pesquisadores brasileiros em Química.

\begin{tabular}{|c|c|c|c|c|c|}
\hline Periódico & $\begin{array}{l}\text { Total de } \\
\text { Artigos }\end{array}$ & $\begin{array}{c}\text { Percentual } \\
\%\end{array}$ & País & Temática & $\begin{array}{c}\text { Fator de } \\
\text { Impacto } \\
2017 \\
\end{array}$ \\
\hline Química Nova & 2470 & 5,75 & Brasil & $\begin{array}{c}\text { Química } \\
\text { Multidisciplinar }\end{array}$ & 0.646 \\
\hline $\begin{array}{c}\text { Journal of The Brazilian } \\
\text { Chemical Society }\end{array}$ & 1683 & 3,92 & Brasil & $\begin{array}{c}\text { Química } \\
\text { Multidisciplinar }\end{array}$ & 1.444 \\
\hline $\begin{array}{c}\text { Revista Brasileira de } \\
\text { Farmacognosia - Brazilian } \\
\text { Journal of Pharmacognosy }\end{array}$ & 667 & 1,55 & Brasil & Química Medicinal & 1.596 \\
\hline $\begin{array}{c}\text { Journal of Thermal Analysis } \\
\text { and Calorimetry }\end{array}$ & 598 & 1,39 & Hungria & $\begin{array}{c}\text { Química } \\
\text { Analítica/Físico- } \\
\text { Química }\end{array}$ & 2.209 \\
\hline $\begin{array}{l}\text { Journal of Magnetism and } \\
\text { Magnetic Materials }\end{array}$ & 506 & 1,18 & Holanda & $\begin{array}{c}\text { Ciência dos } \\
\text { Materiais } \\
\text { Multidisciplinar }\end{array}$ & 3.046 \\
\hline $\begin{array}{c}\text { Materials Research - Ibero- } \\
\text { American Journal of } \\
\text { Materials }\end{array}$ & 488 & 1,14 & Brasil & $\begin{array}{c}\text { Ciência dos } \\
\text { Materiais } \\
\text { Multidisciplinar }\end{array}$ & 1.103 \\
\hline $\begin{array}{l}\text { Journal of Applied Polymer } \\
\text { Science }\end{array}$ & 464 & 1,08 & $\begin{array}{l}\text { Estados } \\
\text { Unidos }\end{array}$ & $\begin{array}{l}\text { Ciência dos } \\
\text { Polímeros }\end{array}$ & 1.901 \\
\hline $\begin{array}{c}\text { Journal of } \\
\text { Ethnopharmacology }\end{array}$ & 458 & 1,07 & Irlanda & Química Medicinal & 3.115 \\
\hline Talanta & 454 & 1,06 & Inglaterra & Química Analítica & 4.244 \\
\hline $\begin{array}{c}\text { Polímeros - Ciência e } \\
\text { Tecnologia } \\
\end{array}$ & 452 & 1,05 & Brasil & $\begin{array}{l}\text { Ciência dos } \\
\text { Polímeros }\end{array}$ & 0.700 \\
\hline $\begin{array}{l}\text { Todos os demais } \\
\text { periódicos }\end{array}$ & 34714 & 80,82 & -- & -- & -- \\
\hline Total & 42954 & 100,00 & -- & -- & -- \\
\hline
\end{tabular}

Fonte: dados da pesquisa, 2016. Dados sobre Fator de Impacto coletados do JCR em 2018.

\footnotetext{
${ }^{1}$ Os dados referentes ao idioma dos periódicos científicos foram consultados no JCR da Clarivate Analytics.
} 
O Fator de impacto dos periódicos, publicado anualmente no Journal Citation Reports (JCR) da Clarivate Analytics, é um indicador utilizado por muitas áreas do conhecimento como critério de apreciação da produção intelectual - inclusive na área Química - quando da avaliação da pós-graduação brasileira feita pela CAPES. Esse indicador é a razão entre a quantidade de citações recebidas por um periódico no ano corrente e o número de documentos citáveis publicado por ele nos dois anos anteriores. Considerando-se que ele é impulsionado pelo processo de comunicação científica de cada área do conhecimento e que cada uma das áreas apresenta características próprias, especialmente no que se refere aos seus hábitos de citação e à publicação de suas pesquisas, o Fator de Impacto somente pode ser comparado entre periódicos de uma mesma especialidade.

Uma das formas de se analisar o Fator de Impacto dos periódicos de diferentes áreas e subáreas do conhecimento é por meio da comparação do posicionamento deles dentro de quartis (dado que também é fornecido pelo JCR). Neste contexto, entre o pequeno núcleo de periódicos que mais publicaram artigos da Química brasileira, a maioria $(76,76 \%)$ encontrase posicionada nos quartis 1 e 2 por Fator de Impacto em sua respectiva subárea. Resultado que evidencia, portanto, a importância e relevância internacional das pesquisas brasileiras em Química, considerando-se que seus artigos foram publicados principalmente em periódicos com alto Fator de Impacto em suas respectivas subáreas. Adiciona-se a isso que os dados sobre investimento em ciência são diferentes em cada país e que, portanto, impactam de forma distinta nas escolhas que os pesquisadores fazem dos tópicos e métodos de suas pesquisas e, consequentemente, dos veículos em que conseguem publicá-las.

A análise da coautoria brasileira com países estrangeiros retrata o processo de internacionalização da ciência nacional e a inserção de cientistas brasileiros em redes mundiais de pesquisa. A coautoria pode ser um elemento estimulador do conhecimento da produção científica nacional por pesquisadores de outras nações, pois permite uma visibilidade maior e, consequentemente, um impacto mais elevado da produção nacional. Diante disso, apura-se que entre os 42.954 artigos brasileiros em Química no período, $75,73 \%$ são de coautoria exclusiva de pesquisadores filiados a instituições brasileiras, enquanto $24,27 \%$ foram publicados em coautoria com pesquisadores estrangeiros de 104 diferentes países. 0 alto percentual de coautoria nacional pode ser explicado pelos fatores descritos no estudo de Sidone et al. (2016) como determinantes para escolha da colaboração nacional em detrimento da internacional, tais como: as barreiras linguísticas e culturais, a dimensão territorial continental e o elevado número de pesquisadores em um mesmo país.

Apesar do baixo percentual de artigos em coautoria com países estrangeiros, quando se analisa a evolução temporal nas coautorias, constata-se que houve um crescimento total de 107,92\% entre 2004 e 2013. O crescimento foi maior em $2007(10,00 \%)$ e 2008 $(18,48 \%)$, e menor a cada ano até chegar a 2012, quando novamente a coautoria cresceu mais significativamente (10,59\%). Ademais, percebe-se que os países europeus têm sido, ao longo dos dez anos, os principais parceiros de pesquisa científica brasileira em Química, com crescimento de $78,23 \%$ no período completo. 0 continente americano é o segundo em quantidade de artigos publicados com a Química brasileira e representa um aumento da coautoria da ordem de 105,79\% entre 2004 e 2013. Até 2005, Ásia era um dos continentes que não apresentava muitos artigos em coautoria com a Química brasileira e, por isso, estava em terceira posição em número de artigos publicados com o Brasil. Porém, em 2006, a quantidade de artigos em coautoria cresceu em $72 \%$ e, em 2009 , em $75,61 \%$. No período completo o crescimento foi de $208,70 \%$, ou seja, superior ao aumento do continente europeu e americano, embora a quantidade absoluta de artigos ainda seja baixa, e o seu total de artigos represente somente $12 \%$ do total do continente europeu e $19 \%$ dos artigos americanos. África e Oceania têm uma evolução bastante similar e em níveis bastante baixos. 


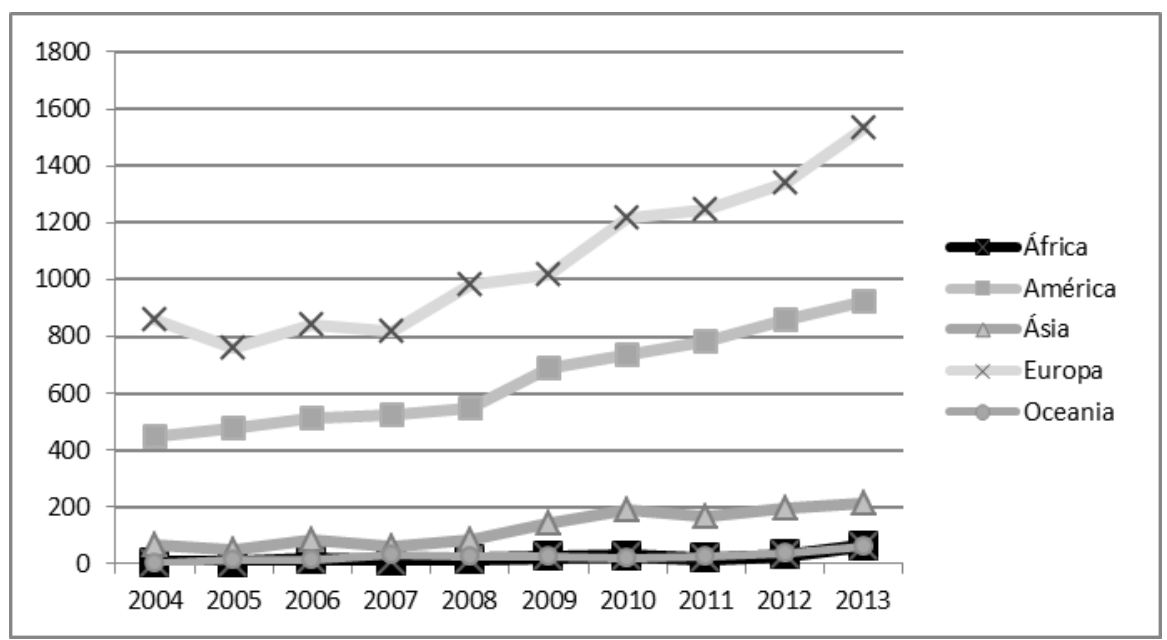

Figura 1: Evolução temporal dos artigos brasileiros em coautoria com países estrangeiros, por continente.

Fonte: dados da pesquisa, 2016.

A maior parte dos artigos publicados em coautoria com outros países é do tipo bilateral (81\%), ou seja, a Química brasileira publica majoritariamente artigos com a colaboração de um país estrangeiro por artigo. Depois se destaca a coautoria trilateral com $15 \%$ do total de artigos; somente $4 \%$ dos artigos foram publicados em coautoria multilateral e totalizam 407 artigos. Entre os países que mais publicaram em coautoria bilateral com o Brasil estão os Estados Unidos (12,88\%), seguido pela França $(9,11 \%)$, Portugal $(7,82 \%)$ e Espanha (7,79\%). 0 fato dos Estados Unidos ser o principal parceiro do Brasil, em números absolutos, pode ser decorrência deste ser o país que apresenta o maior número de documentos publicados no mundo, em todos os anos de análise (2004-2013); ou por ser o primeiro no ranking de países com maior produtividade em Química entre 2004 e 2007 e o segundo entre 2008 e 2013, perdendo somente para a China nos últimos cinco anos estudados (SCImago, [2015]).

Além disso, observa-se que países que mais publicaram em coautoria com a Química brasileira são, também, os principais parceiros do Brasil quando se considera toda a produção científica nacional. Na pesquisa de Vanz (2009), os Estados Unidos foi o principal país coautor da produção nacional, seguido pela França, Reino Unido e Alemanha. Da mesma forma, Glanzel et al. (2006) verificaram que, entre os países que não pertencem a América Latina, o Brasil colaborou especialmente com os Estados Unidos, França, Reino Unido, Alemanha, Itália e Portugal. Diante disso, a Química nacional apresenta a coautoria com resultados similares aos da produção científica nacional.

\section{CONSIDERAÇÕES FINAIS}

Esta pesquisa teve o intuito conhecer as principais características da Química brasileira no que se refere ao seu processo de comunicação científica e à sua inserção na comunidade internacional, bem como seu estágio de desenvolvimento no período de uma década. Nesse sentido, o perfil das publicações químicas brasileiras foi traçado com base nos 42.954 artigos publicados entre 2004 e 2013 e que se encontram indexados na WoS. Com isso, diversos aspectos puderam ser observados, tais como: produtividade da área, distribuição geográfica das principais instituições produtoras de conhecimento, idiomas de publicação, canais de comunicação utilizados e a coautoria.

O crescimento linear da produção científica brasileira em Química e a sua taxa de crescimento geométrico anual demonstram que a área tem progredido constantemente e aumentado principalmente no número de pesquisas realizadas com o passar dos anos. Além disso, a Química tem sido uma das ciências que mais contribuiu com a produção científica nacional, considerando-se seu percentual de $15,5 \%$ do total produzido no país. Por outro lado, o Índice de Atividade permite refletir que, embora o crescimento na produção científica 
venha ocorrendo, a proporção ainda é inferior quando comparada com a média da produção mundial e também com as principais ciências desenvolvidas no país, tais como, a Agricultura.

A partir da análise de produtividade das regiões brasileiras pode-se comprovar a grande desigualdade existente no país, tanto no que diz respeito à pesquisa científica quanto às universidades, à pós-graduação e aos grupos de pesquisa da área. A Região Sudeste é a que concentra a maior parte da produção científica em Química $(57,00 \%)$ em oposição à Região Norte que publicou somente $1,48 \%$ dos artigos. A soberania da Região Sudeste sobre as demais é motivada por diversos fatores, como os de caráter econômico e institucional. Esta região abarca a maior parte dos recursos humanos especializados, as principais instituições de pesquisa do país, uma quantidade maior de empresas (polo econômico nacional), além de receber uma quantidade maior de investimentos.

A busca pela visibilidade e pela internacionalização das pesquisas brasileiras em Química pode ser constatada pelo idioma de publicação, pelos periódicos científicos utilizados e pela coautoria internacional. 0 inglês é a língua predominante entre os artigos publicados e os periódicos estrangeiros são os principais veículos de comunicação dos artigos da área, especialmente os periódicos publicados nos Estados Unidos e Inglaterra. Embora os periódicos estrangeiros sejam predominantes no corpus da pesquisa, cabe destacar a grande importância dos periódicos nacionais da área na divulgação das pesquisas brasileiras. A internacionalização também pode ser percebida pela coautoria das pesquisas brasileiras com pesquisadores dos cinco continentes, embora numa proporção bem menor do que a coautoria entre pesquisadores de dentro do país.

Considerando o cenário esboçado nesta pesquisa, constata-se que os investimentos feitos pelo Brasil em ciência e tecnologia têm trazido resultados ao longo dos anos, pelo menos é claramente observável no caso da Química, onde há crescimento na produção científica, especialmente em periódicos com inserção internacional.

Uma etapa posterior de análise dos investimentos demandará que se estude o impacto dessa produção na própria ciência, por meio das citações recebidas, e, quiçá, também o seu impacto na sociedade como um todo, por meio da transferência de tecnologia.

\section{REFERÊNCIAS}

\section{ASSOCIAÇÃO BRASILEIRA DE INDÚSTRIA QUÍMICA. 0 Desempenho da indústria química brasileira em 2014. São Paulo: ABIQUIM, 2015.}

BRASIL. Ministério da Ciência, Tecnologia e Inovações e Comunicações. Indicadores Nacionais de Ciência, Tecnologia e Inovação. Brasília, DF: MCTIC, 2017. Disponível em:<http://www.mctic.gov.br/mctic/export/sites/institucional/indicadores/arquivos/Indi cadores-2017.pdf>. Acesso em: 19 jun. 2018.

CONTINI, Elisio; SÉCHET, Patrick. Ainda há um longo caminho para a ciência e tecnologia no Brasil. Revista Brasileira de Pós-Graduação, v. 2, n. 3, p. 30-39, mar. 2005. Disponível em: <http://ojs.rbpg.capes.gov.br/index.php/rbpg/article/view/57>. Acesso em: 19 jun. 2018.

FUNDAÇÃO DE AMPARO À PESQUISA DO ESTADO DE SÃO PAULO. Análise da produção científica a partir de publicações em periódicos especializados. In: __. Indicadores de ciência e tecnologia e inovação em São Paulo. São Paulo: FAPESP, 2011. V. 1, cap. 4, p. 172.

GLANZEL, Wolfgang et al. Science in Brazil. Part 1: a macro-level comparative study. Scientometrics, v. 67, n. 1, p. 67-86, 2006. Disponível em: <http://link.springer.com/article/10.1007\%2Fs11192-006-0055-7>. Acesso em: 19 jun. 2018.

GLANZEL, Wolfgang; SCHUBERT, András. A new classification scheme of science fields and subfields designed for scientometric evaluation purposes. Scientometrics, v. 56, n. 3, p. 357 367, $2003 . \quad$ Disponível em: <http://link.springer.com/article/10.1023\%2FA\%3A1022378804087>. Acesso em: 19 jun. 2018.

LETA, Jacqueline. Indicadores de desempenho, ciência brasileira e a cobertura das bases informacionais. Revista USP, n. 89, p. 62-77, mar./maio 2011. Disponível em: 
<http://rusp.scielo.br/scielo.php?script=sci_arttext\&pid=S0103-

99892011000200005\&lng=pt\&nrm=iso>. Acesso em: 04 jun. 2018.

LETA, Jacqueline. Brazilian growth in the mainstream science: the role of human resources and national journals. Journal Scientometrics Research, v. 1, n. 1, p. 44-52, Sept./Dec. $2012 . \quad$ Disponível em: <https://www.jscires.org/sites/default/files/JSciRes_2012_1_1_44_111101.pdf >. Acesso em: 01 jun. 2017.

LETA, Jacqueline; De Meis, L. A profile of science in Brazil. Scientometrics, v. 35, n. 1, p. 3344, 1996. Disponível em: <http://link.springer.com/article/10.1007\%2FBF02018231>. Acesso em: 04 jun. 2018.

LETA, Jacqueline et al. A macro-level study of science in Brazil: seven years later. Encontros Bibli: revista eletrônica de biblioteconomia e ciência da informação, v. 18, n. 36, p. 51-66, jan./abr. $2013 . \quad$ Disponível em: <https://periodicos.ufsc.br/index.php/eb/article/view/1518-

2924.2013v18n36p51/26596>. Acesso em: 04 jun. 2018.

LETA, Jacqueline et al. Science in Brazil. Part 2: sectoral and institutional research profiles. Scientometrics, v. 67, n. 1, p. 87-105, 2006. Disponível em: <http://link.springer.com/article/10.1007\%2Fs11192-006-0051-y>. Acesso em: 19 jun. 2018.

MOED, Henk F. Citation analysis in research evaluation. Amsterdam: Springer, 2005.

MUELLER, Suzana Pinheiro Machado. Métricas para a ciência e tecnologia e o financiamento da pesquisa: algumas reflexões. Encontros Bibli: Revista Eletrônica de Biblioteconomia e Ciência da Informação, Florianópolis, ed. esp., p. 116-128, 2008. Disponível em: $<$ https://periodicos.ufsc.br/index.php/eb/article/view/1518-

2924.2008v13nesp1p24/1593>. Acesso em: 19 jun. 2018.

NATIONAL SCIENCE FOUNDATION. Science and engineering indicators 2018. Alexandria, VA: NSF, 2018.2 Disponível em: $<$ https://www.nsf.gov/statistics/2018/nsb20181/assets/nsb20181.pdf>. Acesso em: 27 jun. 2018.

NORONHA, Daisy Pires; MARICATO, João de Melo. Estudos métricos da informação: primeiras aproximações. Encontros Bibli: revista eletrônica de Biblioteconomia e Ciência da Informação, ed. esp., p. 116-128, 2008. Disponível em: <https://periodicos.ufsc.br/index.php/eb/article/view/1518-2924.2008v13nesp1p116>. Acesso em: 19 jun. 2018.

SCImago. Journal \& Country Rank. [S.l.: SCImago, 2015]. Disponível em: $<$ http://www.scimagojr.com/index.php>. Acesso em: 05 abr. 2015.

SIDONE, Otávio José Guerci et al. A ciência nas regiões brasileiras: evolução da produção e das redes de colaboração científica. Transinformação, v. 28, n. 1, p. 15-31, jan./abr. 2016. Disponível em: <http://periodicos.puccampinas.edu.br/seer/index.php/transinfo/article/view/2415/2225>. Acesso em: 19 jun. 2018.

TESTA, James. The globalization of Web of Science: 2005-2010. [Philadelphia, PA]: Thompson Reuters, 2011. Disponível em: <http://wokinfo.com/essays/globalization-ofweb-of-science/>. Acesso em: 14 nov. 2015.

VANZ, Samile Andrea de Souza. As redes de colaboração científica no Brasil. 2009. $204 \mathrm{f}$ Tese (Doutorado)- Programa de Pós-Graduação em Comunicação e Informação, Faculdade de Biblioteconomia e Comunicação, Universidade Federal do Rio Grande do Sul, Porto Alegre, 2009.

VARGAS, Rosely A. et al. The role of national journals on the rise in brazilian agricultural science publications in Web of Science. Journal of Scientometric Research, v. 3, n. 1, p. 2836, Jan./Apr. $2014 . \quad$ Disponível em: 
<https://www.jscires.org/sites/default/files/JSciRes_2014_3_1_28_143698.pdf >. Acesso em: 19 jun. 2018.

Editores do artigo: Enrique Muriel-Torrado, Edgar Bisset Alvarez, Camila Barros. 